\title{
Hybrids of cationic porphyrins with nanocarbons
}

\author{
Beata Girek • Wanda Sliwa
}

Received: 2 January 2015/Accepted: 13 February 2015/Published online: 17 March 2015

(c) The Author(s) 2015. This article is published with open access at Springerlink.com

\begin{abstract}
In the review hybrids of cationic porphyrins (i.e. porphyrins functionalized by quaternary pyridinium groups) with nanocarbons such as fullerenes, carbon nanotubes and graphene are described. Selected examples of these species are characterized in regard of their properties and possible applications.
\end{abstract}

Keywords Allotropes - Carbon nanotubes - Fullerene · Graphene $\cdot$ Nanocarbons · Porphyrins

\section{Introduction}

Porphyrins are planar tetrapyrrolic macrocycles that have interesting properties and value for applications in various fields. They are promising in the design of sensors [1] and they show catalytic properties [2]; some metal porphyrins may be used for analytical purposes [3]. The reactivity of porphyrins enables synthesis of valuable systems, useful in many areas [4-10], e.g. design of solar cells [11, 12] and nanowires [13].

Cationic porphyrins, i.e. porphyrins meso-functionalized by quaternary azaaromatic units, due to the presence of four positive charges are of interest in the construction of next generation photosensitizers [14]. Cationic porphyrins exist as free ones, and as metalloporphyrins.

B. Girek · W. Sliwa ( $\square)$

Institute of Chemistry, Environmental Protection and

Biotechnology, Jan Długosz University in Czestochowa, Armii

Krajowej 13/15, 42-200 Czestochowa, Poland

e-mail: w.sliwa@ajd.czest.pl
The representative compound of cationic porphyrins is meso-tetrakis( $N$-methyl-4-pyridinium porphyrin (TMPyP), in this review referred to as A. Among hybrids of cationic porphyrins, those with nanocarbons are a topic of present review.

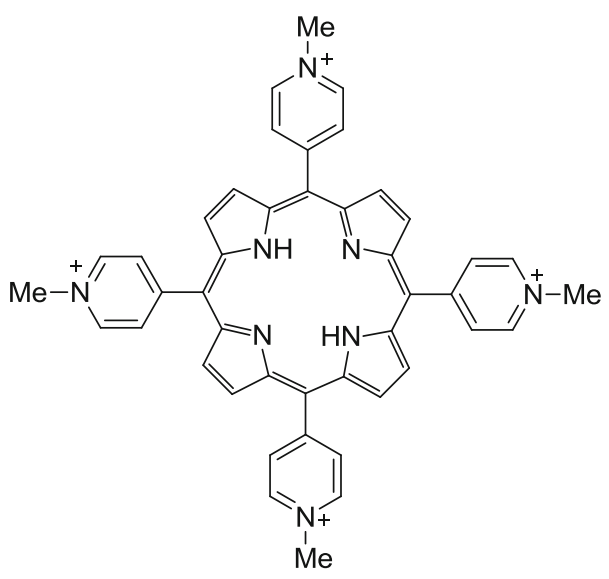

A

A growing attention is paid today to interaction of cationic porphyrins with nucleic acids [15]. Cationic porphyrin $\mathbf{A}$ is a known ${ }^{1} \mathrm{O}_{2}$ photosensitizer, effectively used in photodynamic therapy (PDT), generating singlet oxygen for selective destruction of localized tumors [16].

It is noteworthy that antimicrobial photodynamic therapy (aPDT) is now emerging as an alternative to antibiotics; in this procedure the cationic photosensitizers such as cationic porphyrins interact in the excited state with molecular oxygen to produce singlet oxygen that kills the microbial cells [17].

Among a variety of other applications of porphyrins in medicinal field [18] one may mention the use of 
luminescence of porphyrins for fluorescence diagnostic magnetic resonance imaging [19] and for design of selfilluminating fluorophores suitable for in vivo applications [20].

Nanocarbons, belonging to carbon allotropes include zero-dimensional (0D) fullerenes, one-dimensional (1D) carbon nanotubes and two-dimensional (2D) graphene. Nanocarbons have attracted recently a growing attention due to their unique electronic, optical, thermal and chemical properties, promising for their applications in a variety of areas [21].

The smallest species, i.e. fullerenes consist of bent $\mathrm{sp}^{2}$ carbon atoms. From fullerenes to graphene the strain at $\mathrm{sp}^{2}$ carbon atoms decreases; the surfaces of fullerenes and graphene have different reactivities. In fullerenes attempts to release strain by formation of $\mathrm{sp}^{3}$ carbon centers exist, therefore fullerenes have anomalously large reactivity, while in graphene no strain at carbon atoms is observed, i.e. no tendency for $\mathrm{sp}^{3}$ hybridization occurs, and consequently, graphene is less reactive than fullerenes [22].

Nanocarbons are today a topic of an intense research, and a considerable progress in this area is observed. Due to valuable properties they may find applications in various fields; one should point out the importance of these materials so from theoretical and practical viewpoints.

Fullerenes, carbon nanotubes and graphene are of interest in the study of artificial photosynthesis and solar energy conversion, in the construction of electronic, optoelectronic, photovoltaic and sensing devices [23] and in the study of advanced energy conversion (in design of solar cells and fuel cells) and energy storage (in design of batteries and supercapacitors) [24]. Fullerenes and carbon nanotubes are promising as acceptor materials in organic photovoltaics; the donor-acceptor blends with a polymer donor and a fullerene or single walled carbon nanotubes (SWCNT) acceptor were reported [25].

Carbon nanotubes and graphene may be applied in photocatalytic reduction of $\mathrm{CO}_{2}$ (produced as an emission from use of hydrocarbon fuels) to hydrocarbon fuels [26]. Carbon nanotubes and graphene are of interest for application in mass and energy transport. They are examples of low dimensional species promising in the reduction of dimensionality of the material [27].

Carbon nanotubes and graphene are investigated in order to facilitate charge transport across abiotic-biotic interfaces [28], they are promising for use in liquid-phase chemiluminescence systems [29] and for design of nanoresonator sensors [30]. The studies of interactions of surfaces of carbon nanotubes and graphene with metal atoms were reported in view of their application in high frequency electronic devices, fuel cells as well as memory and energy devices [31].

Today the use of solar energy is crucial to solve the energy problems for a sustainable society; molecular devices employing hybrids of nanocarbons, (i.e. fullerenes, single wall carbon nanotubes SWCNTs and graphene), acting as electron acceptors, with photosensitizers, acting as electron donors, are promising for this aim. In the experiments concerning the above theme, the light-induced electron transfer processes of nanocarbon hybridized with photosensitizers, have been shown to be very useful for this purpose.

Fullerenes act as electron acceptors for electron donors such as cationic porphyrins and phthalocyanines to yield characteristic radical ion pairs, suitable for construction of artificial photosynthetic systems. SWCNTs are also electron acceptors for cationic porphyrins and phthalocyanines. Graphene provides a reaction field of a wide $\pi$ system for formation of hybrids.

One should emphasize that the electron transfer processes are of a great importance for efficient light-energy harvesting devices such as photovoltaic solar cells [32].

In the paper the noncovalent assemblies of cationic porphyrins with nanocarbons, i.e. hybrids of cationic porphyrins with nanocarbons are described in view of their properties and possible applications. The review is a continuation of our former papers concerning cationic porphyrins [33-35], as well as quaternary azaaromatic rotaxanes [36-39] and viologens [40].

\section{Hybrids of cationic porphyrins with fullerenes}

Fullerenes are widely investigated due to their unique structure and interesting properties. They are promising for application in industrial chemistry and electronics; one should also mention construction of polymer/fullerene solar cells. Fullerene derivatives are of interest as antioxidative agents in biological systems. Encapsulation of various species inside fullerenes leads to endohedral fullerenes, valuable in material science and medicine, and in the field of organic photovoltaics. A reflection of the above properties of fullerenes are many reports describing their applications [41-47]. Porphyrins form with fullerenes covalently bound compounds [48-50] or hybrids of porphyrins with fullerenes [51-58], these latter being the theme of the present section. 
Hybrids of cationic porphyrins with fullerenes are described below; in these selected examples the dendrofullerenes were used.

\section{Example 1.1}

It was established that octacationic zinc porphyrin $\mathrm{ZnP}^{8+}$ forms with anionic $\mathrm{C}_{60}$ dendrofullerenes the porph.f and $\mathrm{porph}_{2} \cdot \mathrm{f} \quad\left(\mathrm{porph}=\mathrm{ZnP}^{8+}, \mathrm{f}=\right.$ fullerene $)$ assemblies by electrostatic and charge-transfer interactions; due to these interactions the obtained assemblies are very stable [59, 60]. One should point out that in such assemblies also hydrophobic interaction should be taken into account.

As $\mathrm{C}_{60}$ dendrofullerenes the compounds $\mathbf{1 - 3}$ have been used. The formation of the assemblies was investigated by gel electrophoresis. For example, the aggregation of $\mathrm{ZnP}^{8+}$ with 2 yields the assembly porph $\mathbf{2}$, and with $\mathbf{3}$ the assemblies porph $\mathbf{3}$ and $\operatorname{porph}_{2} \cdot \mathbf{3}$ are obtained.

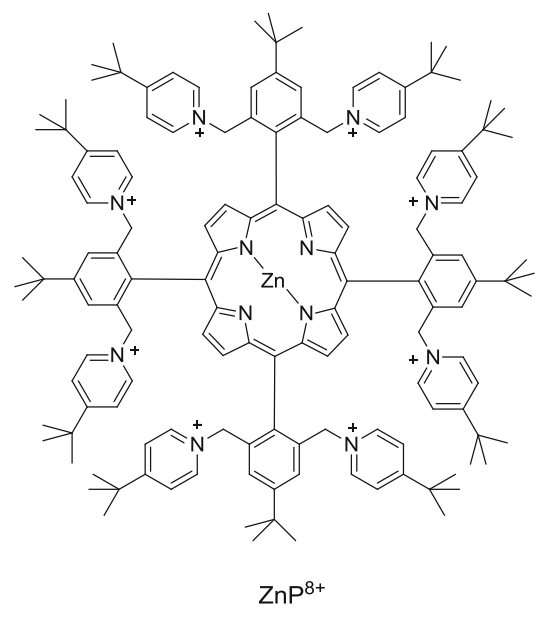

The results of experiments have shown that radical ion pairs $\mathrm{ZnP}^{+} / \mathrm{C}_{60}^{--}$are formed. All radical ion-pair states decay to their singlet ground states without passing through the intermediate triplet excited states of $\mathrm{ZnP}^{8+}$ or $\mathrm{C}_{60}[59,60]$.

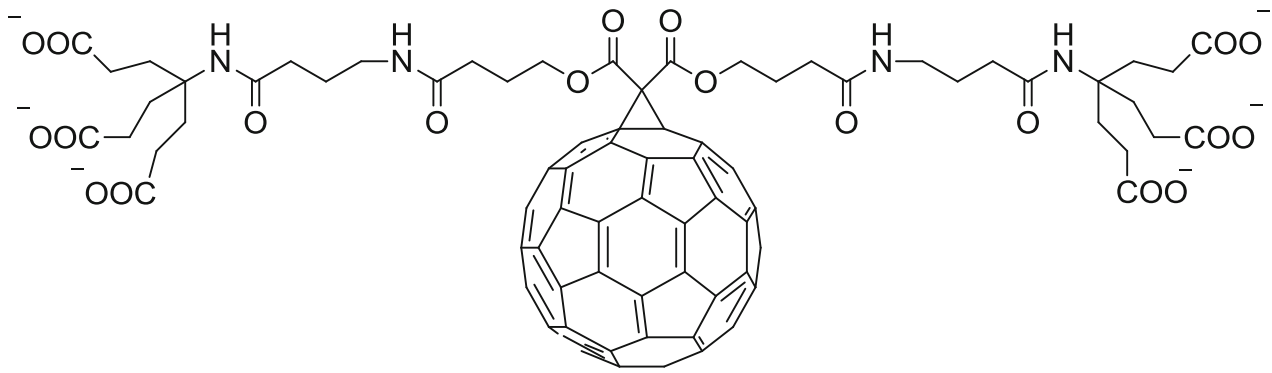

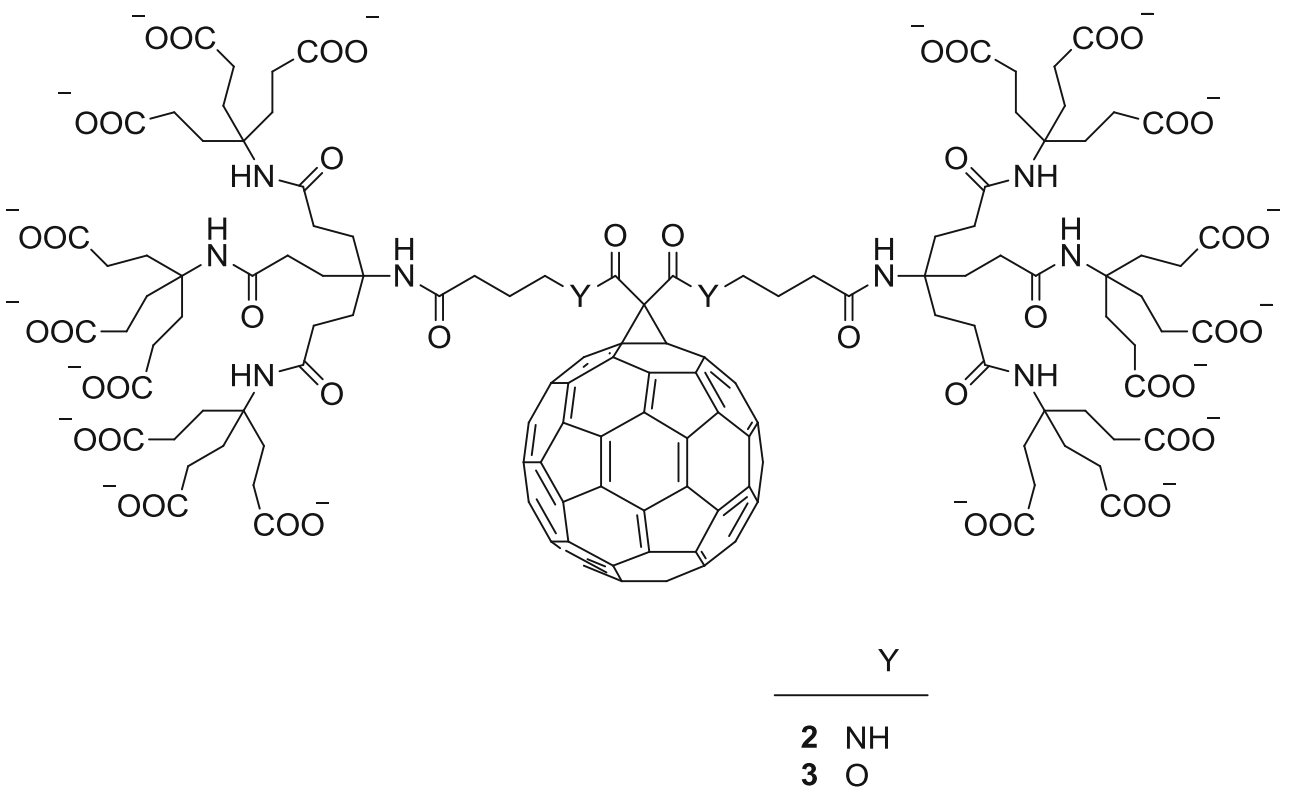


Example 1.2

The layer-by-layer (LbL) deposition of positively and negatively charged oligoelectrolyte multilayer (OEM) films was investigated in view of their assembly and disassembly behavior. The LbL technique is a simple and very efficient wet-coating method.

The LbL process involves the alternate deposition of cationic and anionic species from a solution [61-65]. Due to electrostatic attraction and repulsion, the oppositely charged polyions can self-assemble on solid surfaces, e.g. on metal or glass. Formation of iterative dipping circles makes it possible to obtain the deposited thin films composed of alternating monolayers of polycations and polyanions. This easy and cheap method affords advanced materials based on polyelectrolyte multilayer films.

The octacationic zinc porphyrin $\mathrm{ZnP}^{8+}$ was used as a positively charged oligoelectrolyte, and compounds 4-6 served as negatively charged oligoelectrolytes. By use of electrolytes 5 and $\mathbf{6}$ containing the porphyrin chromophore, the deposition could be easily followed by UV-Vis spectroscopy [66]. However, using LbL method, polymers serving as charged building blocks are polydisperse and often do not adopt a defined shape within the deposited layers, therefore in experiments the
LbL technique was extended to monodisperse oligoelectrolytes with defined structures. It is worth noting that the application of so-called reporter oligoelectrolytes is important, since they enable the precise monitoring of the film assembly by using spectroscopic methods.

Besides the assembly, also the first study of disassembly was made; this investigation is promising in incorporation of bioactive molecules at a given inter-layer position, since after removal of the outer layers the bioactive molecules can be released. Such drug delivery is interesting for biomedical use.

For LbL assembly of molecular oligoelectrolytes, the layers of porphyrin $\mathrm{ZnP}^{8+}$ and 4, 5 or 6 were deposited on planar silica substrates using the alternate dipping method. For investigation of possible application of OEMs as drug delivery systems, the biologically active pamidronate 7 used in the bone metastasis was employed as an anionic building block. The porphyrin $\mathrm{ZnP}^{8+}$ served as a cationic component and at the same time as a reporter electrolyte, therefore the detection of the anionic component occurred indirectly. It was found that the absorbance of $\mathrm{ZnP}^{8+}$ is enhanced when the number of $\mathrm{ZnP}^{8+}$ layers increases; the correlation is linear. This behavior enables the regulation of the amount of deposited 7 by the number of layers. 
<smiles>O=C([O-])CCCC(CCC(=O)[O-])(CCC(=O)[O-])NC(=O)CCC(CCC(=O)[O-])(CCC(=O)[O-])NC(=O)CCC(CCC(=O)[O-])(CCC(=O)[O-])NC(=O)CCC(=O)[O-]</smiles>

4

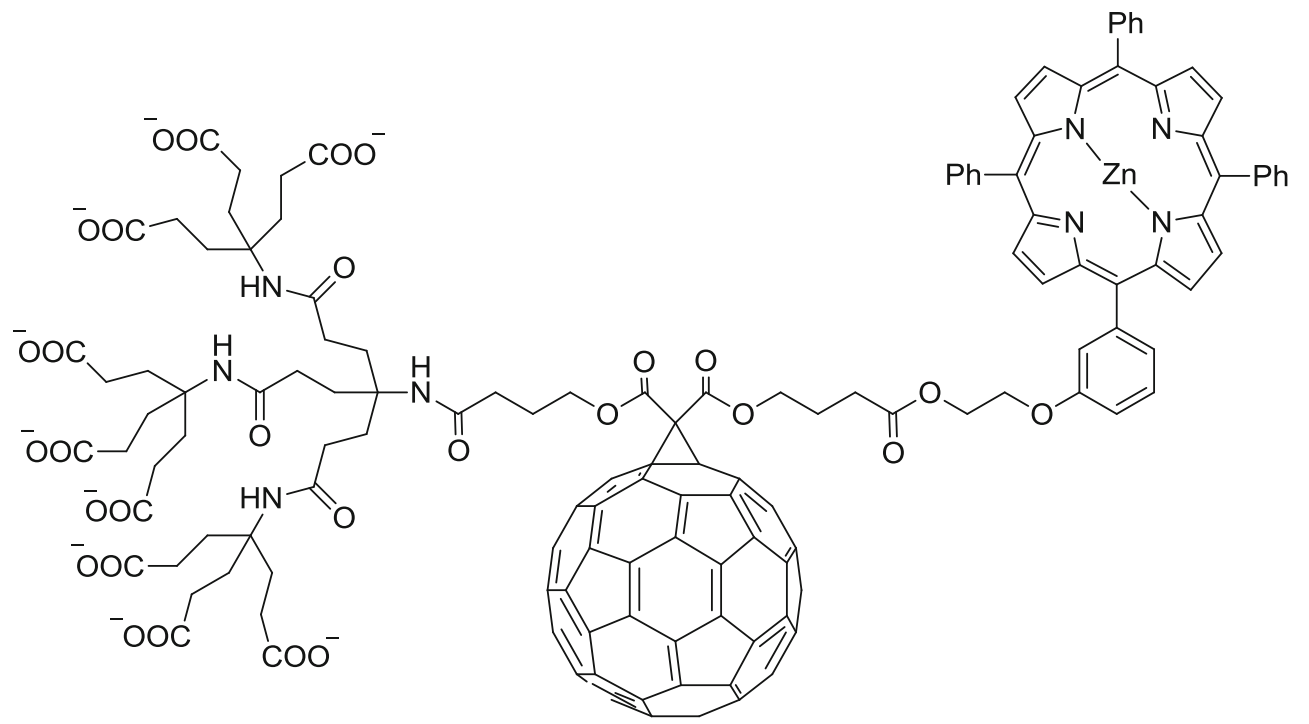

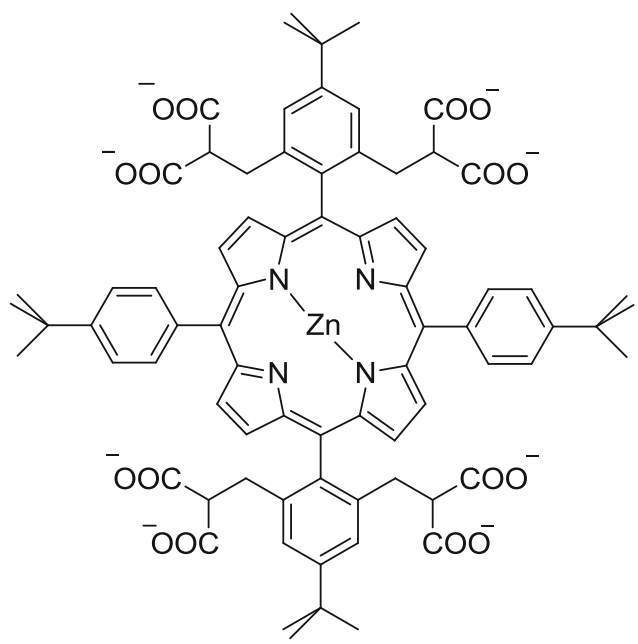

5<smiles>NCCC(O)(P(=O)(O)O)P(=O)(O)O</smiles>

7
It was established that the use of chromophore containing electrolytes, in particular porphyrins allows the observation of both assembly and disassembly of OEMs by optical spectroscopy; the compounds containing chromophore serve here as reporter electrolytes. One should point out that oligoelectrolytes used are monodisperse, and various synthetic procedures enable modification of properties of OEMs. It is of interest that the investigated OEMs may show the time dependent release of active components, this behavior being promising for drug delivery [66].

\section{Hybrids of cationic porphyrins with carbon nanotubes}

Carbon nanotubes have interesting mechanical, electronic and optical properties, therefore they are promising for design of composite materials, drug carriers as well as sensing and energy conversion devices. They are investigated with the aim to obtain photo- and redox-responsive materials. Carbon nanotubes, due to their unique structural and electronic properties are of interest for design of hybrids useful in various areas. The applications of nanotubes are today a topic of an enormous amount of reports [67-72]. 
SWCNTs may be chemically modified for use as nanosized building blocks. This process may be performed by covalent or noncovalent functionalization. The covalent functionalization is rather disadvantageous because of structural changes of nanotubes and loss of some of their unique properties. To overcome this difficulty the noncovalent functionalization of nanotubes is used, this process leads to hybrids of nanotubes with functionalizing agents.

The noncovalent functionalization of nanotubes usually proceeds by $\pi$-stacking interactions of an organic molecule or polymer with nanotube walls. It is preferable when the attached molecule has an extended $\pi$-electron system of bonds, in this respect the use of porphyrins is convenient. It is noteworthy that in porphyrin/nanotube hybrids, the existence of a light-induced charge transfer between porphyrins and SWCNTs is promising for their application in solar energy conversion.

In the study of mechanism of the hybrid formation it was found that the interaction of nanotubes and por-
Example 2.1

It is known that assembling composites of chromophores with carbon nanotubes is a crucial process for construction of photoelectronic devices, biosensors and electron storage devices [81]; for assembling of such composites it is necessary to solubilize nanotubes because they have only low solubility in most solvents. For this purpose the nanostructured LbL ultrathin film consisting of chromophores and single-walled carbon nanotubes (SWNTs) was obtained [62$65,82]$. As chromophores the cationic porphyrin 8 and anionic sodium copper chlorophyllin 9 were used.

The LbL film 8-SWNT/9-SWNT was built from noncovalently adsorbed composites 8-SWNT and 9-SWNT. For this purpose SWNTs were dissolved in water soluble cationic $\mathbf{8}$ and anionic $\mathbf{9}$, and the obtained solution served for electrostatic LbL multilayer preparation. The composites were highly dispersed due to existence of $\pi-\pi$ interactions [82].

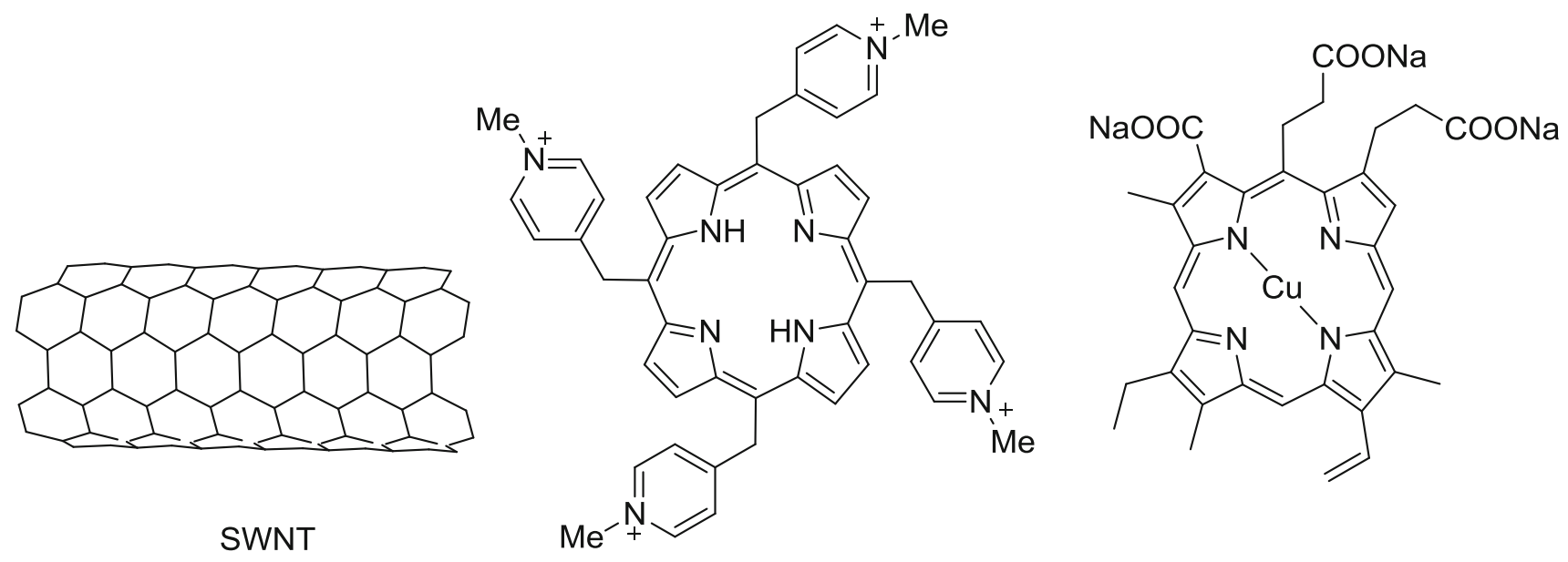

phyrins with charged side residues is much stronger than in the case of neutral porphyrins. Quantum-chemical calculations have shown that the hybrids formed by nanotubes with charged molecules are stabilized due to strong cation- $\pi$ interactions. It is noteworthy that such complexes are highly stable in water [73]. Hybrids of porphyrins with carbon nanotubes are today intensively studied owing to their promising properties [7480].

Hybrids of cationic porphyrins with carbon nanotubes are a topic of an intense research, below some examples are presented.
A strong quenching of $\mathbf{8}$ and $\mathbf{9}$ fluorescence resulting from their interaction with SWNT was observed. Due to the efficient charge separation and electron transfer in the above LbL film electrodes, the photocurrent generation is enhanced as compared with $\mathbf{8 / 9}$ film electrodes without SWNT.

\section{Example 2.2}

In the study of hybrids of porphyrins with carbon nanotubes the interaction of porphyrins $\mathrm{A}$ and meso5,10,15,20-tetraphenylporphyrin $\mathbf{1 0}$ with zigzag single- 
walled carbon nanotube (SWNT) has been investigated by resonance Raman spectroscopy and by ab initio and molecular dynamic calculations [73].

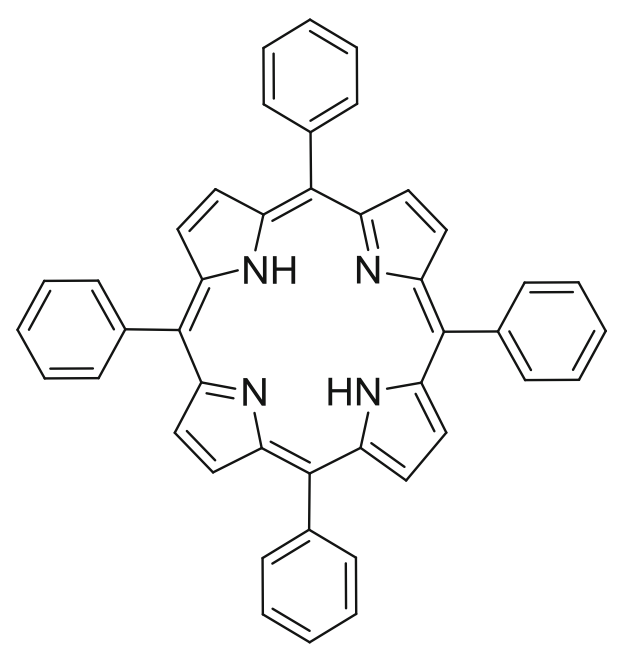

10

The results have shown that the interaction of A with SWNT is stronger than the interaction of $\mathbf{1 0}$ with SWNT, since between A and SWNT the cation- $\pi$ attraction exists. In the molecule $A$ the strong cation- $\pi$ attraction leads to the saddling; the saddled structure of A provides a closer contact between the charged groups of A with the SWNT surface. The formation of A/SWNT complex in the aqueous solution has been modeled by the molecular dynamics method, showing its stability in the water environment.

\section{Example 2.3}

Photoinduced electron transfer in ion-paired porphyrin/ SWNT hybrids has been studied. The donor-acceptor hybrids have been built from water-soluble cationic or anionic porphyrins $\mathrm{MA}^{4+}$ or $\mathrm{MS}^{4-}$, respectively, serving as electron donors, and from noncovalently functionalized SWNTs serving as electron acceptors. In a first step, SWNTs were solubilized by $\pi-\pi$ stacking of pyrene functionalized by anionic $\left(\mathrm{COO}^{-}\right)$or cationic $\left(\mathrm{NH}_{3}{ }^{+}\right)$ groups. Cationic or anionic porphyrins $\mathrm{MA}^{4+}$ or $\mathrm{MS}^{4-}$ were ion-paired with functionalized SWNT/pyr ${ }^{-}$and SWNT/pyr ${ }^{+}$systems to give porphyrin-SWNT donor-acceptor hybrids $\mathrm{MA}^{8+} / \mathrm{SWNT} / \mathrm{pyr}^{-}$or $\mathrm{MS}^{8+} / \mathrm{SWNT} / \mathrm{pyr}^{+}$ [83]. The steady-state and time-resolved emission studies have revealed an efficient quenching of the singlet excited state of porphyrins in hybrids. The transient absorption spectra have shown the one-electron oxidation of porphyrins with a simultaneous one-electron reduction of SWNT.
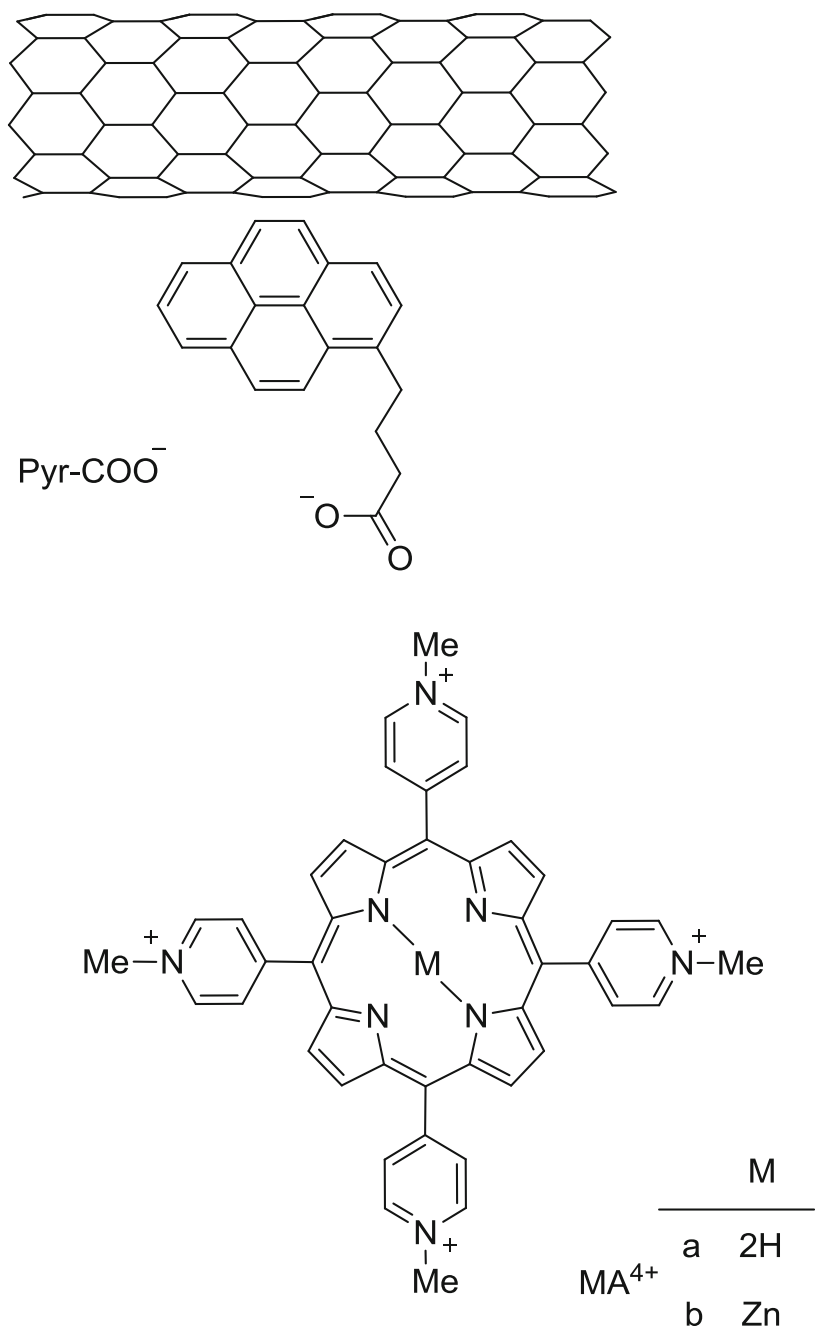


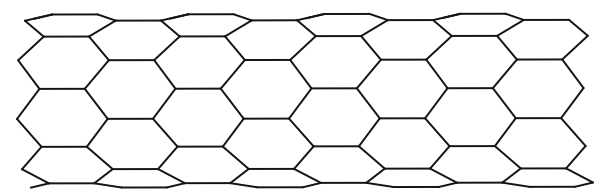<smiles>[NH3+]CCNC(=O)CCCc1ccc2ccc3cccc4ccc1c2c34</smiles>

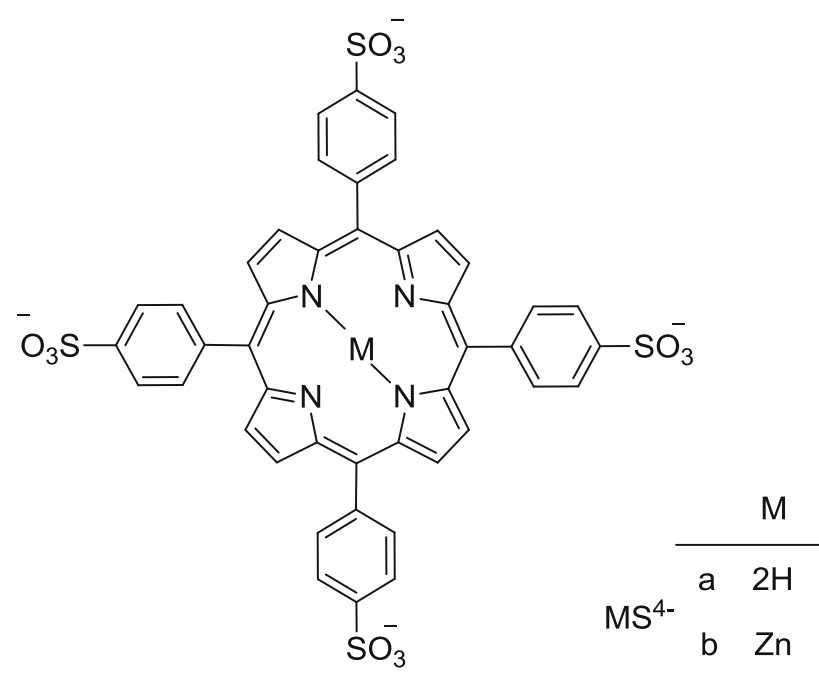

The charge separation process was further confirmed by an electron mediator (methyl or hexylviologen dication $\mathrm{MV}^{2+}$ or $\mathrm{HV}^{2+}$, respectively) and an electron-hole shifter 1-benzyl-1,4-dihydronicotinamide (BNAH) in water or DMF, used as solvents. The photoinduced processes resulted in the accumulations of radical cations $\mathrm{MV}^{+}$and $\mathrm{HV}^{+}$, due to the electron-pooling in the presence of a sacrificial electron donor. This behavior shows the photoinduced electron transfer and enables photocatalytic applications of the above systems.

\section{Example 2.4}

The immobilization of porphyrin $\mathrm{A}$ on the carbon nanohorn $(\mathrm{CNH})$ was investigated in order to design donor-acceptor $\mathrm{CNH}$-based hybrids for managing electronic interactions in environmentally friendly aqueous media. In the experiments the water soluble porphyrin A has been immobilized by $\pi-\pi$ stacking interactions on carbon nanohorns $(\mathrm{CNHs})$; this process does not disrupt their $\pi$-electronic network [84]. 


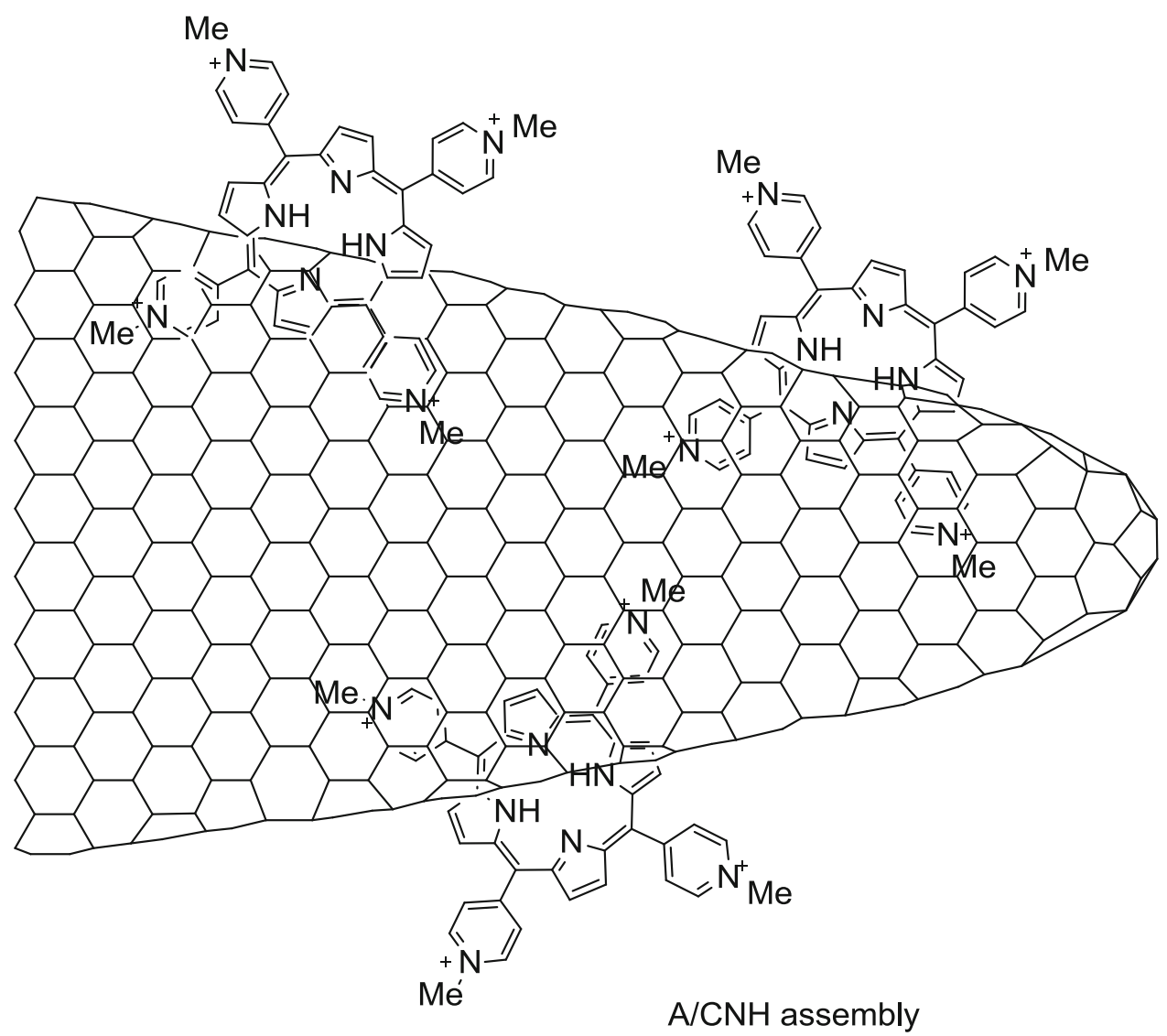

The efficient fluorescence quenching of the A unit in the $\mathrm{A} / \mathrm{CNH}$ assembly suggests charge separations from the photoexcited A to $\mathrm{CNH}$. The photoinduced chargeseparation processes within the illuminated $\mathrm{A} / \mathrm{CNH}$ hybrids, i.e. oxidation of the porphyrin and reduction of the nanohorns were studied by transient absorption spectroscopy. In the presence of $\mathrm{MV}^{2+}$ and a hole trap, the accumulation of the reduced form of methyl viologen was observed by the illumination of A-CNH; this behavior shows the electron migration from the initially formed charge-separated state [84].

The CNHs were produced by $\mathrm{CO}_{2}$ laser ablation of graphite in the absence of metal catalyst under the inert argon atmosphere. The mild sonication of $\mathrm{CNH}$ in aqueous solution of $\mathrm{A}$ afforded the water soluble $\mathrm{A} / \mathrm{CNH}$ hybrid. It was found that the morphology of $\mathrm{CNH}$ was retained upon immobilization of $\mathrm{A}$, this suggests that the stacking of $\mathrm{A}$ onto $\mathrm{CNH}$ does not alter the aggregation of CNHs. The high solubilization of $\mathrm{CNHs}$ in aqueous solution shows that the surface of CNHs is covered by A.

It is noteworthy that $\mathrm{CNHs}$ are more convenient for design of nanomaterials than carbon nanotubes, since they are of a high purity due to the absence of any metal nanoparticles during the laser ablation production, and they have heterogenous surface structure resulting from highly strained conical ends. It is important that the rough surface structure of $\mathrm{CNH}$ aggregates enables the better dispersion of CNHs in liquid media than in the case of tightly bundled carbon nanotubes.

In investigation of systems able to mimic natural photosynthesis, the hybrids built from porphyrins and CNHs are of interest. They contain $\mathrm{CNHs}$ behaving as electron acceptors and porphyrins as electron donors which act as light-harvesting antennas capturing visible light and transducing the excitation energy. It should be pointed out that the above $\mathrm{A} / \mathrm{CNH}$ assemblies are promising for use in solar energy conversion.

\section{Example 2.5}

Formation of hybrids of cationic, water soluble metalloporphyrins $\mathrm{MP}^{8+}$, namely $\mathrm{FeP}^{8+}$ and $\mathrm{CoP}^{8+}$ with SWNTs was investigated. For this purpose SWNTs were functionalized with anionic pyrenes from among 11a-d and treated with metalloporphyrins $\mathrm{FeP}^{8+}$ or $\mathrm{CoP}^{8+}$. It was observed that the resulting $\mathrm{MP}^{8+} / \mathrm{SWNT} / \mathrm{pyr}^{-}$assemblies form stable hybrid structures in aqueous media $\left(\mathrm{pyr}^{-}=\right.$pyrene). An important feature of this procedure is that an efficient 
exfoliation of the initial bundles affords isolated nanohybrid structures [85].

Upon excitation of the above $\mathrm{MP}^{8+} / \mathrm{SWNT}_{\mathrm{pyr}}{ }^{-}$hybrid with visible light, the rapid intrahybrid electron transfer from the photoexcited $\mathrm{MP}^{8+}$ to SWNT occurs. This fact causes the reduction of the electron-accepting SWNT and, at the same time, the oxidation of the electron donating $\mathrm{MP}^{8+}$.

a<smiles>O=C([O-])c1ccc2ccc3cccc4ccc1c2c34</smiles>

b<smiles>O=C([O-])Cc1ccc2ccc3cccc4ccc1c2c34</smiles>

11

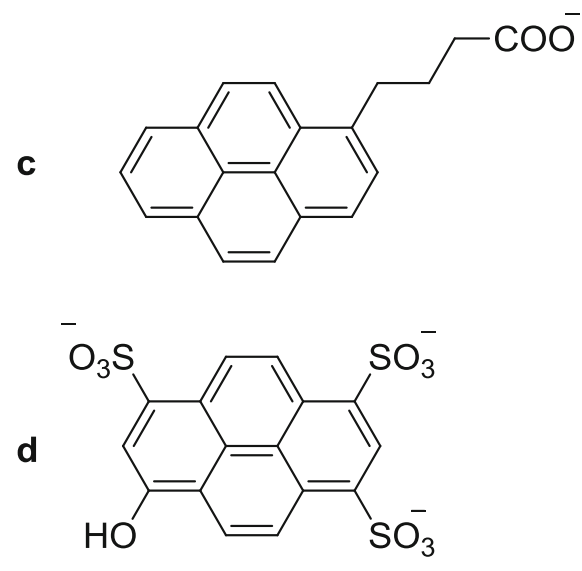

\section{Hybrids of cationic porphyrins with graphene}

Graphene is a single layer of graphite, where carbon atoms are arranged in a honeycomb lattice; owing to its specific electronic and mechanical properties, e.g. high charge carrier mobility, graphene is today a topic of an intense research [86-92]. One can say that 2D graphene was wrapped to form OD fullerenes, was rolled to form 1D carbon nanotubes, and

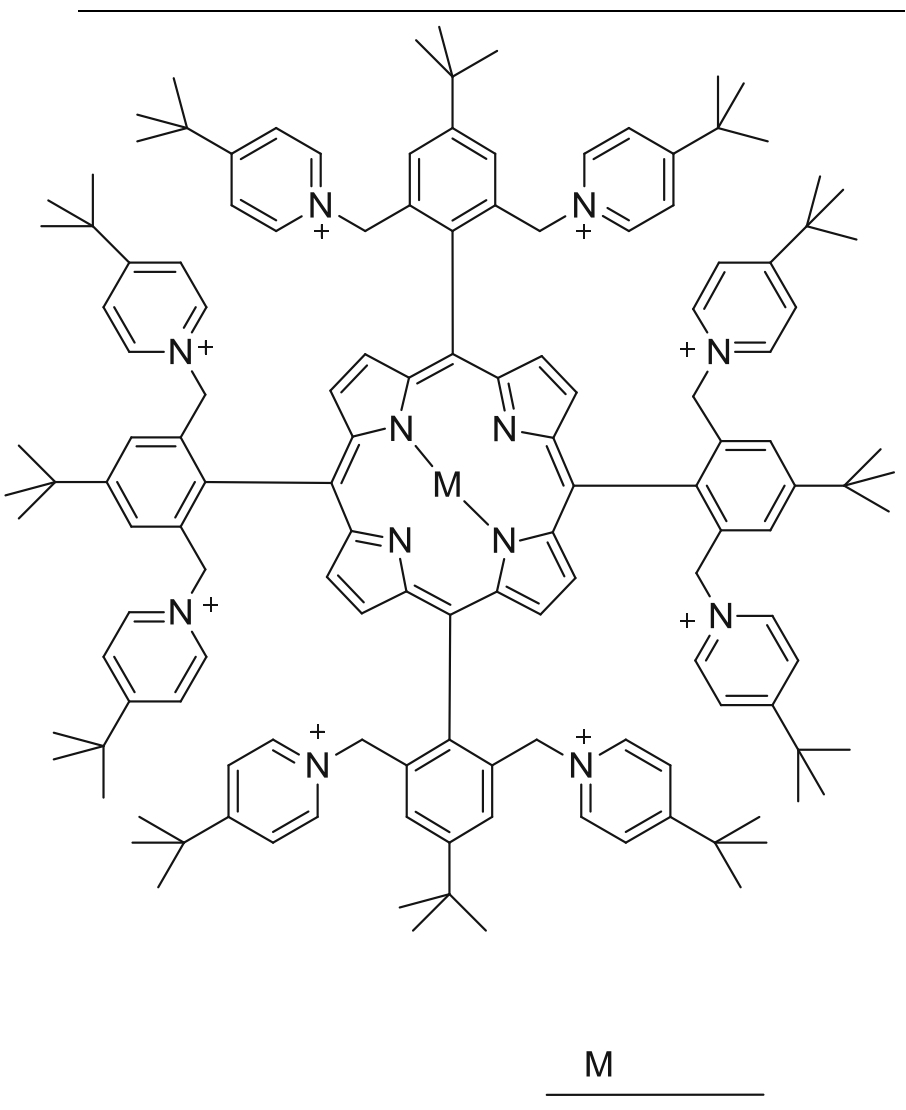

$\mathrm{Fe} \mathrm{FeP}^{8+}$

$\mathrm{Co} \mathrm{CoP}^{8+}$

axial ligands are omitted for clarity

One should note the importance of SWNT templates bearing carboxylate or sulfonate groups. These negative groups act as promoters for suspending SWNT samples in aqueous media and as anchors interacting with pyridinium headgroups present in metalloporphyrins. Pyrene compounds are strong fluorophores therefore they are useful sensitive markers in the performed experiments, the fluorescence spectroscopy being a very convenient tool for investigation of the above electron donor-acceptor interactions. stacked to form 3D graphite [93]. In contrast to fullerenes or nanotubes, graphene is a large anisotropic, very flexible material which may be bent or folded [94].

The selected techniques for preparation of graphene and related species are presented below [95]. The completely insoluble natural graphite powder upon oxidation affords graphite oxide.

Graphene oxide (GO) is the single-layered graphite oxide which can be prepared by the exfoliation of graphite 
oxide. GO having many functional groups such as hydroxyl, aldehyde, carboxyl, epoxy is obtained by exposing graphite powder to strong oxidant solutions, e.g. $\mathrm{KMnO}_{4} /$ $\mathrm{H}_{2} \mathrm{SO}_{4}$ followed by $\mathrm{H}_{2} \mathrm{O}_{2}(30 \%)$. Exfoliation is performed by sonication of GO dispersion.

Chemically converted graphene (CCG) is prepared by reduction of GO suspensions e.g. with hydrazine; in this way a majority of the oxygen functional groups undergoes elimination and the conjugated structure of GO is restored.

Carboxylic acid modified GO (CGO) is obtained by sonication of GO under basic conditions, followed by neutralization with $\mathrm{HCl}$; it selectively reserves the carboxylic acid functional groups.

The unique electronic system of graphene results from its high quality $2 \mathrm{D}$ crystal lattice in which electrons can move without being scattered off, therefore high electrical conductivity exists. As drawbacks of graphene may be considered its severe stacking as well as its complete insolubility in all solvents including water. Therefore in the investigation of graphene the main topics are its exfoliation from graphite and its solubilization. Chemical methods of exfoliation involve the use of strong acids [96], ionic liquids [97], surfactants [98] or organic solvents [99]; also tip sonication induces graphene exfoliation affording dispersion in organic solvents [100].

In order to improve the chemical compatibility of graphene with diverse media, it is necessary to develop its well-dispersed form. For this purpose covalent and noncovalent functionalization of graphene with various molecules and nanomaterials was investigated in water and in organic solvents [101-103]. may be used, in this way the electronic network of graphene is not disrupted [104]. Noncovalent functionalization, as compared with covalent one, preserves the intrinsic properties of graphene and improves its solubilization via hydrophobic interactions and $\pi-\pi$ stacking.

In the noncovalent functionalization the planar aromatic organic molecules are employed; they interact through numerous $\pi-\pi$ van des Waals forces with the graphitic framework and promote spontaneous exfoliation [105]. For a noncovalent functionalization of graphene (or of GO) the planar aromatic molecules such as porphyrins [106, 107]; phthalocyanines [108] or pyrenes [109] may be used.

Describing graphene it seems noteworthy to mention graphene-coated metal NPs and graphenes modified by metal NPs; four examples concerning this theme will be given ( $N P=$ nanoparticle).

In the study of graphene-coated metal NPs two examples will be shown. In the first one the graphene-coated CoNPs 12 which can be functionalized are presented; e.g. they can react with 4-nitrobenzene diazonium tetrafluoroborate to give $p$-nitrophenyl derivative $\mathbf{1 3}$, which upon reduction with elemental sulfur affords aminoderivative $\mathbf{1 4}$ useful for peptide coupling [21, 110-112]. The mechanism of the graphene-coated CoNPs reaction with aryl diazonium salts involves an electron transfer from graphene to the diazonium ion; upon evolution of nitrogen the reactive phenyl radical is formed which reacts with graphene surface.

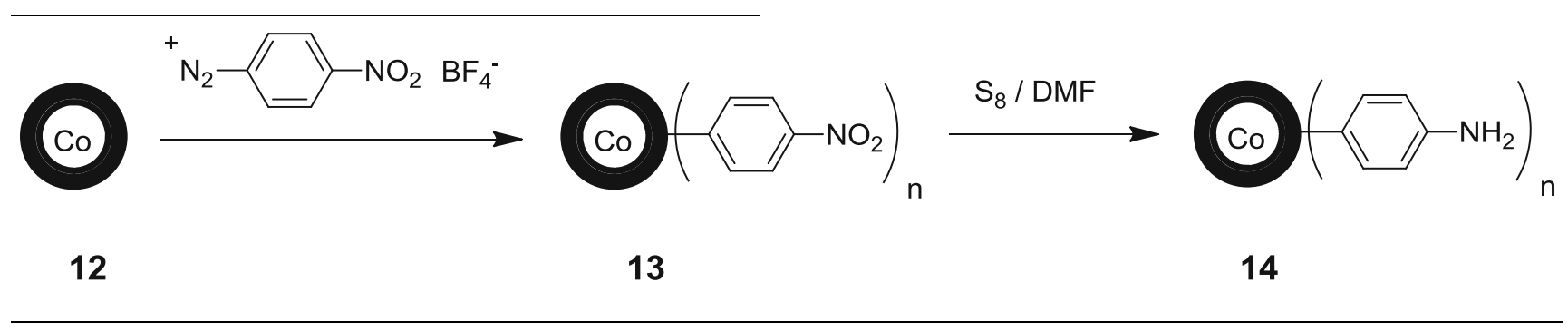

Functionalization of graphene offers its new application possibilities. However, the extensive covalent functionalization of graphene introduces $\mathrm{sp}^{3}$ defects in its lattice; this behavior decreases its high conductivity [104]. To overcome this inconvenience, the noncovalent functionalization
In the next example the graphene-coated CoNPs functionalized by (azidomethyl)benzene 15 undergo "click" reaction with stable radical propargyl ether TEMPO $\mathbf{1 6}$ yielding $\mathbf{1 7}$ which is an efficient catalyst for oxidation of primary and secondary alcohols [113]. 


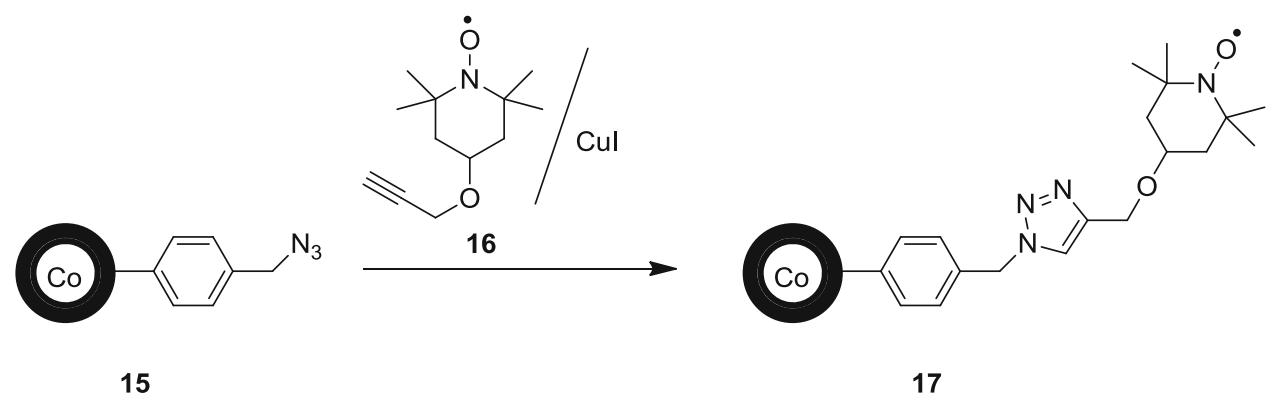

In the study of graphenes modified by NPs, two examples, i.e. graphenes modified by AuNPs and by AgNPs will be shown. Graphene sheets composed from 2 to 10 layers may serve for preparation of graphenes modified by NPs. Chemical exfoliation of graphite in aqueous medium $\left(\mathrm{H}_{2} \mathrm{SO}_{4} / \mathrm{KMnO}_{4}\right.$, then $\left.30 \% \mathrm{H}_{2} \mathrm{O}_{2}\right)$ afforded $\mathrm{GO}$; the subsequent thermal treatment of $\mathrm{GO}\left(1050{ }^{\circ} \mathrm{C}, 30 \mathrm{~s}\right)$ promoted further exfoliation.

The oxygen functionalities (hydroxyl and epoxy groups) situated on the graphene surface are reactive sites for chemical modification and for deposition of NPs [114]. The presence of the oxygen functionalities is important for the growth of $\mathrm{Au} \mathrm{NPs}$; it was observed that AuNPs cannot deposit on the totally reduced graphene sheets. After reduction with hydrazine, the graphene as an aqueous suspension was treated with $\mathrm{HAuCl}_{4}$ solution, and the subsequent reaction with sodium citrate afforded graphene modified by AuNPs. This material may serve as a substrate for surface-enhanced Raman scattering (SERS) [114].

Another method was used for preparation of graphene modified by AgNPs. GO sheets have been anchored onto $\mathrm{TiO}_{2}$ films. It was observed that upon UV illumination of $\mathrm{TiO}_{2} / \mathrm{GO}$ films, the photogenerated electrons from $\mathrm{TiO}_{2}$ are captured by GO. [115, 116]. These electrons not only reduce GO to RGO, but also become stored across its $\mathrm{sp}^{2}$ network. The stored electrons can serve for reduction of metal ions to metal NPs.

In the presence of silver ions, the AgNPs begin deposit onto GO surface opposite $\mathrm{TiO}_{2}$, since $\mathrm{GO}$ is able to transport electrons through its plane. The above procedure is possible due to the unique property of GO/RGO to shuttle electrons in a direction orthogonal to its plane, and transfer electrons to $\mathrm{Ag}^{+}$ions. The formed semiconductor-graphene-metal (SGM) film is valuable for catalysis and sensor use. These SGM films, tested as SERS sensors produced considerable target molecule signal enhancement, in this way enabling detection of their nanomolar concentrations.

It seems that the above examples concerning graphenecoated NPs and graphenes modified by NPs may be considered as a supplement to the wide field of graphene applications [117-122].

Hybrids of cationic porphyrins with graphene are today intensively studied. Among many works concerning graphenes functionalized by porphyrins [123-126], a special attention has been paid to graphenes noncovalently functionalized by cationic porphyrins, i.e. hybrids of cationic porphyrins with graphene [127-131].

\section{Example 3.1}

The noncovalent functionalization of graphene with porphyrins was widely investigated [130, 131]. In order to elucidate this process the interaction of different chemical types of graphene, i.e. GO, CCG and CGO with porphyrin A was studied. It was observed that the intermolecular interaction occurs immediately upon mixing graphene with $\mathrm{A}$; in this process $\mathrm{A}$ is immobilized on the graphene surface via electrostatic and $\pi-\pi$ stacking interactions.

It is worth noting that functional groups on the surface and edge of GO, CCG and CGO play an important role in functionalization of graphenes with $\mathrm{A}$. The strong fluorescence quenching of A upon its interaction with graphene is due to the efficient electron or energy transfer from excited state A to graphene. The red shift of Soret band of A occurring at its interaction with graphene depends on the kind of functional groups of graphene and decreases in the order CCG > CGO > GO [95].

\section{Example 3.2}

In further experiments porphyrin A was integrated via Coulombic interactions to exfoliated graphene, and the possible photoinduced electron/energy transfer phenomena have been investigated [106]. It is known that the wettability of graphene can be tuned as a function of $\mathrm{pH}$ from the organic to aqueous phase by addition of amphiphilic block copolymer poly(isoprene b-acrylic acid), further 
referred to as pol [106]. The stable aqueous dispersions of graphene were prepared using block copolymer pol in the form of its anion at alkaline $\mathrm{pH}$, then the cationic $\mathrm{A}$ was integrated to the system taking advantage of opposite charges of graphene dispersions and $\mathrm{A}^{4+}$. As a result, the aqueous dispersion of graphene/pol/A $\mathrm{A}^{4+}$ assembly was formed. It was established by photoluminescence experiments that in this assembly the graphene layers act as electron acceptor, and $\mathrm{A}$ is the photoexcited electron donor. resonance Raman signal (SERRS) sensitivity of porphyrin A $(\mathrm{RGO}=$ reduced $\mathrm{GO} ; \mathrm{NP}=$ nanoparticle $)$. The SERSactive materials include noble metal NPs, such as silver or gold NPs. These NPs provide a localized surface plasmon resonance leading to a large local electromagnetic field which can enhance Raman scattering signals, enabling single molecule SERS [133]. Metal NPs have been combined with graphene to give composites able to SERS sensing [115].<smiles>C#CC(CC(C)(C)C=C(C)CC(C)(C)C)(C(=O)[O-])C(C)(C)C=CCCCCCC</smiles>

pol<smiles>C[n+]1ccc(-c2c3nc(c(-c4cc[n+](C)cc4)c4ccc([nH]4)c(-c4cc[n+](C)cc4)c4nc(c(-c5cc[n+](C)cc5)c5ccc2[nH]5)C=C4)C=C3)cc1</smiles>
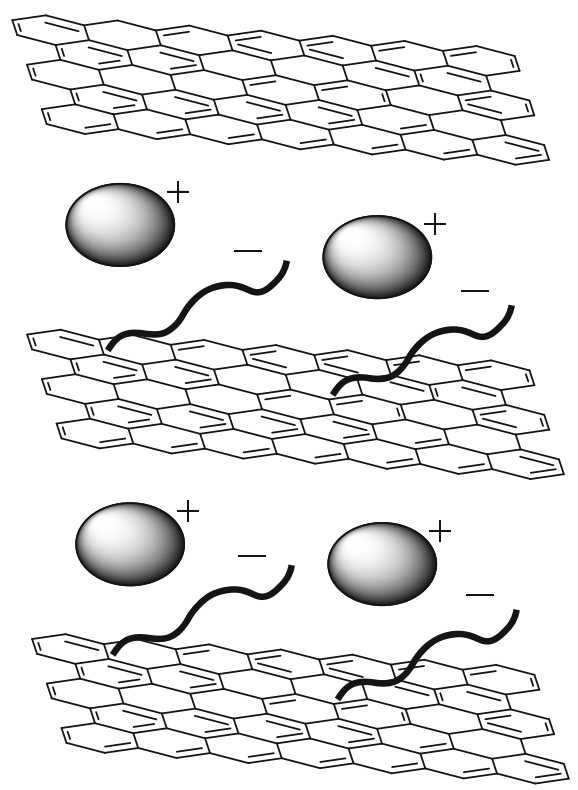

graphene/pol// ${ }^{4+}$ assembly
The absorption and fluorescence spectroscopic measurements have shown the presence of electronic communication between $\mathrm{A}$ and graphene in the ground and excited states. Basing on experimental results and taking into account the reported redox potential of graphene [132], one may conclude that the quenching of $\mathrm{A}$ fluorescence results rather from electron transfer than from energy transfer [106].

\section{Example 3.3}

It is known that the selectivity and improved sensitivity of SERS measurements are desirable for analytical and environmental applications. The RGO-AgNP composite has been studied for improvement of surface-enhanced
The RGO-AgNP composite is promising for use as a SERS substrate. Graphene has high surface area, therefore is suitable for dispersion of metal NPs. It was observed that metal NPs can be grown directly on graphene by a simple solution-based approach. The intrinsic ability of RGO to adsorb and complex with molecular species facilitates the enhanced SERRS sensing.

The increased sensitivity for SERS detection using RGOAgNP composite was investigated in terms of RGO-AgNPtarget molecule, i.e. porphyrin A interaction; in experiments RGO was shown to be an effective substrate for dispersing AgNPs. The red shift of the Soret band of A in UV-Vis absorption spectrophotometry, observed upon complexation of A with RGO-AgNP confirms this behavior [134]. It was 
established that the use of RGO-AgNP composite results in a significant SERRS enhancement for target molecule A that undergoes complexation with RGO-AgNP.

\section{Conclusion}

Hybrids of cationic porphyrins with nanocarbons, i.e. fullerenes, carbon nanotubes and graphene showed to be promising for various applications, therefore recently they are a topic of a wide investigation. In view of the intense progress in the field of porphyrins [135-138], fullerenes [139-142], carbon nanotubes [143-146] and graphene [147-150] one may expect the further development of porphyrin hybrids with nanocarbons which could be used e.g. in the area of electronics or photovoltaics.

In a summary it should be pointed out that the theme concerning hybrids of cationic porphyrins with nanocarbons is very large, therefore from among a great number of reports only selected works have been shown in the review. However, one may hope that, although not exhaustive, it would to some extent help to gain better insight into this area, promising for novel, valuable applications.

Open Access This article is distributed under the terms of the Creative Commons Attribution License which permits any use, distribution, and reproduction in any medium, provided the original author(s) and the source are credited.

\section{References}

1. Wang, L., Li, H., Deng, J., Cao, D.: Recent advances in porphyrinderived sensors. Curr. Org. Chem. 17(24), 3078-3091 (2013)

2. Simoes, M.M.Q., Neves, C.M.B., Pires, S.M.G., Neves, M., Graca, P.M.S., Calvaleiro, J.A.S.: Mimicking P450 processes and the use of metalloporphyrins. Pure Appl. Chem. 85(8), 1671-1681 (2013)

3. Valicsek, Z., Horvath, O.: Application of the electronic spectra of porphyrins for analytical purposes: the effects of metal ions and structural distortions. Microchem. J. 107, 47-62 (2013)

4. Fuhrhop, J.-H.: Porphyrin assemblies and their scaffolds. Langmuir 30(1), 1-12 (2014)

5. de la Torre, G., Bottari, G., Sekita, M., Hausmann, A., Guldi, D.M., Torres, T.: A voyage into the synthesis and photophysics of homo- and heterobinuclear ensembles of phthalocyanines and porphyrins. Chem. Soc. Rev. 42(20), 8049-8105 (2013)

6. Berezin, B.D., Zvezdina, S.V., Berezin, M.B.: Double metalligand exchange in solvate complex-metal porphyrin systems. Russ. J. Gen. Chem. 83(7), 1410-1418 (2013)

7. Takanami, T.: Functionalization of porphyrins through $\mathrm{C}-\mathrm{C}$ bond formation reactions with functional group-bearing organometallic reagents. Heterocycles 87(8), 1659-1689 (2013)

8. Yorimisu, H., Osuka, A.: Organometallic approaches for direct modification of peripheral $\mathrm{C}-\mathrm{H}$ bonds in porphyrin cores. Asian J. Organ. Chem. 2(5), 356-373 (2013)

9. Souza, D.P.V., Gomes, M.A.G.B., Goncalves, P.S., Santos, R.P., Maria, E.J., Matos, C.R.R.: Synthesis and biological activity of porphyrins. Mini-Rev. Org. Chem. 10(1), 97-102 (2013)
10. D’Urso, A., Fragalà, M.E., Purrello, R.: From self-assembly to noncovalent synthesis of programmable porphyrins' arrays in aqueous solution. Chem. Commun. 48, 8165-8176 (2012)

11. Giribabu, L., Kanaparthi, R.K.: Are porphyrins an alternative to ruthenium(II) sensitizers for dye-sensitized solar cells? Curr. Sci. 104(7), 847-855 (2013)

12. Hasobe, T.: Porphyrin-based supramolecular nanoarchitectures for solar energy conversion. J. Phys. Chem. Lett. 4(11), 1771-1780 (2013)

13. Fathalla, M., Neuberger, A., Li, S.-C., Schmehl, R., Diebold, U., Jayawickramarajah, J.: Straightforward self-assembly of porphyrin nanowires in water: harnessing adamantane/ $\beta$-cyclodextrin interactions. J. Am. Chem. Soc. 132, 9966-9967 (2010)

14. Kumar, D., Mishra, B.A., Shekar, K.P.C., Kumar, A., Akamatsu, K., Kusaka, E., Ito, T.: Remarkable photocytocoxicity of a novel triazole-linked cationic porphyrin- $\beta$-carboline conjugate. Chem. Commun. 49, 683-685 (2013)

15. Pradines, V., Pratviel, G.: Interaction of cationic manganese porphyrin with G-quadruplex nucleic acids probed by differential labeling of the two faces of the porphyrin. Angew. Chem. Int. Ed. 52, 2185-2188 (2013)

16. Ogawa, K., Kobuke, Y.: Two-photon photodynamic therapy by water-soluble self-assembled conjugated porphyrins. BioMed Res. Int. 2013(125658), 11 (2013)

17. Sperandio, F.F., Huang, Y.-Y., Hamblin, M.R.: Antimicrobal photodynamic therapy to kill Gram-negative bacteria. Recent Pat. Anti-Infect. Drug Discov. 8(2), 108-120 (2013)

18. Tovmasyan, A., Sheng, H., Weitner, T., Arulpragasam, A., Lu, M., Warner, D.S., Vujaskovic, Z., Spasojevic, I., BatinicHaberle, I.: Design, mechanism of action, bioavailabity and therapeutic effects of Mn porphyrin-based redox modulators. Med. Princ. Pract. 22(2), 103-130 (2013)

19. Mironov, A.F.: Lanthanide porphyrin complexes. Russ. Chem. Rev. 82(4), 333-351 (2013)

20. Ptaszek, M.: Rational design of fluorophores for in vivo applications. Prog. Mol. Biol. Transl. Sci. 113, 59-108 (2013)

21. Hoheisel, T.N., Schrettl, S., Szilluweit, R., Frauenrath, H.: Nanostructured carbonaceous materials from molecular precursors. Angew. Chem. Int. Ed. 49, 6496-6515 (2010)

22. Koehler, F.M., Stark, W.J.: Organic synthesis on graphene. Acc. Chem. Res. 46(10), 2297-2306 (2013)

23. Jariwala, D., Sangwan, V.K., Lauhon, L.J., Marks, T.J., Hersam, M.C.: Carbon nanomaterials for electronics, optoelectronics, photovoltaics, and sensing. Chem. Soc. Rev. 42(7), 2824-2860 (2013)

24. Liu, J., Xue, Y., Zhang, M., Dai, L.: Graphitic carbon materials for energy applications. Div. Energy Fuels 58(1), 1190-1191 (2013). Preprints-ACS

25. Ferguson, A.J., Blackburn, J.L., Kopidakis, N.: Fullerenes and carbon nanotubes as acceptor materials in organic photovoltaics. Mater. Lett. 90, 115-125 (2013)

26. Sun, H., Wang, S.: Research advances in the synthesis of nanocarbon-based photocatalysts and their applications for photocatalytic conversion of carbon dioxide to hydrocarbon fuels. Energy Fuels 28(1), 22-36 (2014)

27. Wang, Q.H., Bellisario, D.O., Drahushuk, L.W., Jain, R.M., Kruss, S., Landry, M.P., Mahajan, S.G., Shimizu, S.F.E., Ulissi, Z.W., Strano, M.S.: Low dimensional carbon materials for application in mass and energy transport. Chem. Mater. 26(1), 172-183 (2014)

28. Du, J., Catania, C., Bazan, G.C.: Modification of abiotic-biotic interfaces with small molecules and nanomaterials for improved bioelectronics. Chem. Mater. 26(1), 686-697 (2014)

29. Su, Y., Xie, Y., Hou, X., Lv, Y.: Recent advances in analytical applications of nanomaterials in liquid-phase chemiluminescence. Appl. Spectrosc. Rev. 49(3), 201-232 (2014) 
30. Wang, Q., Arash, B.: A review on applications of carbon nanotubes and graphenes as nano-resonator sensors. Comput. Mater. Sci. 82, 350-360 (2014)

31. Sarkar, S., Moser, M.L., Tian, X., Zhang, X., Al-Hadeethi, Y.F., Haddon, R.C.: Metals on graphene and carbon nanotube surfaces: from mobile atoms to atomtronics to bulk metals to clusters and catalysts. Chem. Mater. 26(1), 184-195 (2014)

32. D'Souza, F., Ito, O.: Photoinduced electron transfer processes of functionalized nanocarbons: fullerenes, nanotubes and graphene. Sci. Prog. 96(4), 369-397 (2013)

33. Girek, B., Sliwa, W.: Noncovalent assemblies of cationic porphyrins with cage macrocycles. J. Incl. Phenom. Macrocycl. Chem. 81, 35-48 (2015)

34. Girek, B., Sliwa, W.: Porphyrins functionalized by quaternary pyridinium units. J. Porphyrins Phthalocyanines 17, 1139-1156 (2013)

35. Sliwa, W., Herman, B., Girek, T.: Porphyrins bearing quaternary azaaromatic moieties. J. Porphyrins Phthalocyanines 11(1), 15-30 (2007)

36. Deska, M., Nowik-Zajac, A., Sliwa, W.: Radical-radical rotaxanes with tetracationic cyclophane ring, and quaternary azaaromatic rotaxanes with cage macrocycles. Arkivoc 1, 264-306 (2014)

37. Deska, M., Nowik-Zajac, A., Sliwa, W.: Donor-acceptor rotaxanes with tetracationic cyclophane ring. Arkivoc 1, 185-242 (2013)

38. Deska, M., Kozlowska, J., Sliwa, W.: Rotaxanes and pseudorotaxanes with threads containing pyridinium units. Arkivoc 1, 294-332 (2013)

39. Deska, M., Kozlowska, J., Sliwa, W.: Rotaxanes and pseudorotaxanes with threads containing viologen units. Arkivoc 1, 66-100 (2013)

40. Sliwa, W., Bachowska, B., Girek, T.: Viologen-based supramolecular structures. Curr. Org. Chem. 16, 1332-1358 (2012)

41. Echt, O., Kaiser, A., Zoettl, S., Mauracher, A., Denifl, S., Scheier, P.: Adsorption of polar and nonpolar molecules on isolated cationic $\mathrm{C} 60, \mathrm{C} 70$, and their aggregates. ChemPlusChem 78(9), 910-920 (2013)

42. Popov, A.A., Yang, S., Dunsch, L.: Endohedral fullerenes. Chem. Rev. 113(8), 5989-6113 (2013)

43. Li, Y.: Fullerene-bisadduct acceptors for polymer solar cells. Chem. Asian J. 8(10), 2316-2328 (2013)

44. Mchedlov-Petrossyan, N.O.: Fullerenes in liquid media: an unsettling intrusion into the solution chemistry. Chem. Rev. 113(7), 5149-5193 (2013)

45. Zhu, S.-E., Li, F., Wang, G.-W.: Mechanochemistry of fullerenes and related materials. Chem. Soc. Rev. 42(18), 7535-7570 (2013)

46. Khlyabich, P.P., Bukhart, B., Rudenko, A.E., Thompson, B.C.: Optimization and simplification of polymer-fullerene solar cells through polymer and active layer design. Polymer 54(20), 5267-5298 (2013)

47. Yamada, M., Akasaka, T., Nagase, S.: Carbene additions to fullerenes. Chem. Rev. 113(9), 7209-7264 (2013)

48. Ichiki, T., Matsuo, Y., Nakamura, E.: Photostability of a dyad of magnesium porphyrin and fullerene and its application to photocurrent conversion. Chem. Commun. 49(3), 279-281 (2013)

49. Brennan, B.J., Liddell, P.A., Moore, T.A., Moore, A.L., Gust, D.: Hole mobility in porphyrin- and porphyrin-fullerene electropolymers. J. Phys. Chem. B 117(1), 426-432 (2013)

50. D'Souza, F., Ito, O.: Multiporphyrins-fullerenes and multiporphyrins-SWCNTs mimicking photosynthetic antenna-reaction center. In: kim, D. (ed.) Multiporphyrin Arrays, pp. 389-437. Pan stanford publishing, singapore (2012)

51. Olguin, M., Zope, R.R., Baruah, T.: Effect of geometrical orientation on the charge-transfer energetics of supramolecular
(tetraphenyl)-porphyrin/C60 dyads. J. Chem. Phys. 138(7), 074306(1-8) (2013)

52. Ito, O., D'Souza, F.: Light harvesting, photosensitized electron transfer in nanocarbon-sensitizer hybrids. ECS J. Solid State Sci. Technol. 2(10), M3063-M3073 (2013)

53. Fukuzumi, S., Ohkubo, K.: Long-lived photoinduced charge separation for solar cell applications in supramolecular complexes of multimetalloporphyrins and fullerenes. Dalton Trans. 42(45), 15846-15858 (2013)

54. Nawaz, M.H., Liu, J., Liu, F., Wang, X., Zhang, W.: Synthesis of porphyrinic polystyrenes and their self-assembly with pristine fullerene (C60). Mater. Lett. 91, 71-74 (2013)

55. Natori, I., Natori, S., Kanasashi, A., Tsuchiya, K., Ogino, K.: Formation of a porphyrin/fullerene light-harvesting system from self-assembly of porphyrin-end-functionalized polycyclohexane and [6,6]-phenyl-C61-butyric methyl ester: effects of microphase separation and $\pi-\pi$ interactions. J Polym. Sci. Part B 51(5), 368-375 (2013)

56. Bassiouk, M., Alvarez-Zauco, E., Basiuk, V.A.: Adsorption of meso-tetraphenylporphines on thin films of C60 fullerene. Appl. Surf. Sci. 275, 374-383 (2013)

57. Wang, C.-L., Zhang, W.-B., Sun, H.-J., Van Horn, R.M., Kulkarni, R.R., Tsai, C.-C., Hsu, C.-S., Lotz, B., Gong, X., Cheng, S.Z.D.: A supramolecular "double-cable" structure with a 12944 helix in a columnar porphyrin-C60 dyad and its application in polymer solar cells. Adv. Energy Mater. 2(11), 1375-1382 (2012)

58. Zope, R.R., Olguin, M., Baruah, T.: Charge transfer excitations in cofacial fullerene-porphyrin complexes. J. Chem. Phys. 137, 084317(1-8) (2012)

59. Sarova, G.H., Hartnagel, U., Balbinot, D., Sali, S., Jux, N., Hirsch, A., Guldi, D.M.: Testing electron transfer within molecular associates built around anionic $\mathrm{C}_{60}$ and $\mathrm{C}_{70}$ dendrofullerenes and a cationic zinc porphyrin. Chem. Eur. J. 14, 3137-3145 (2008)

60. Hartnagel, U., Balbinot, D., Jux, N., Hirsch, A.: Electrophoresis of electrostatically assembled fullerene-porphyrin conjugates. Org. Biomol. Chem. 4, 1785-1795 (2006)

61. Sriwichai, S., Baba, A., Deng, S., Huang, C., Phanichphant, S., Advincula, R.C.: Nanostructured ultrathin films of alternating sexithiophenes and electropolymerizable polycarbazole precursor layers investigated by electrochemical surface plasmon resonance (EC-SPR) spectroscopy. Langmuir 24, 9017-9023 (2008)

62. Olaya, A.J., Schaming, D., Brevet, P.-F., Nagatani, H., Xu, H.J., Meyer, M., Girault, H.H.: Interfacial self-assembly of watersoluble cationic porphyrins for the reduction of oxygen to water. Angew. Chem. Int. Ed. 51, 6447-6451 (2012)

63. Olaya, A.J., Schaming, D., Brevet, P.-F., Nagatani, H., Zimmermann, T., Vanicek, J., Xu, H.-J., Gros, C.P., Barbe, J.-M., Girault, H.H.: Self-assembled molecular rafts at liquid/liquid interfaces for four-electron oxygen reduction. J. Am. Chem. Soc. 134, 498-506 (2012)

64. Olaya, A.J., Ge, P., Gonthier, J., Pechy, P., Corminboeuf, C., Girault, H.H.: Four-electron oxygen reduction by tetrathiafulvalene. J. Am. Chem. Soc. 133, 12115-12123 (2011)

65. Su, B., Hatay, I., Trojánek, A., Samec, Z., Khoury, T., Gros, C.P., Barbe, J.-M., Daina, A., Carrupt, P.-A., Girault, H.H.: Molecular electrocatalysis for oxygen reduction by cobalt porphyrins adsorbed at liquid/liquid interfaces. J. Am. Chem. Soc. 132, 2655-2662 (2010)

66. Rosenlehner, K., Schunk, T., Jux, N., Brettreich, M., Hirsch, A.: Layer-by-layer deposition of molecular oligoelectrolytes-investigation of assembling and degradation behavior. Org. Biomol. Chem. 6, 2697-2705 (2008)

67. Mehra, N.K., Mishra, V., Jain, N.K.: A review of ligand tethered surface engineered carbon nanotubes. Biomaterials 35(4), 1267-1283 (2014) 
68. Ong, Y.T., Yee, K.F., Cheng, Y.K., Tan, S.H.: A review on the use and stability of supported liquid membranes in the pervaporation process. Sep. Purif. Rev. 43(1), 62-88 (2014)

69. Lim, D.-J., Sim, M., Oh, L., Lim, K., Park, H.: Carbon-based drug delivery carriers for cancer therapy. Arch. Pharm. Res. 37(1), 43-52 (2014)

70. Marega, R., Bonifazi, D.: Filling carbon nanotubes for nanobiotechnological applications. New J. Chem. 38(1), 22-27 (2014)

71. Rafiee, R., Moghadam, R.M.: On the modeling of carbon nanotubes: a critical review. Compos. B Eng. 56, 435-449 (2014)

72. Kingston, C., Zepp, R., Andrady, A., Boverhof, D., Fehir, R., Hawkins, D., Roberts, J., Sayre, P., Shelton, B., Sultan, Y., Vejins, V., Wohlleben, W.: Release characteristics of selected carbon nanotube polymer composites. Carbon 68, 33-57 (2014)

73. Karachevtsev, V.A., Zarudnev, E.S., Stepanian, S.G., Glamazda, A.Y., Karachevtsev, M.V., Adamowicz, L.: Raman spectroscopy and theoretical characterization of nanohybrids of porphyrins with carbon nanotubes. J. Phys. Chem. C 114(39), 16215-16222 (2010)

74. Vizuete, M., Gomez-Escalonilla, M.J., Fierro, J.L.G., Atienzar, P., Garcia, H., Langa, F.: Double-well carbon nanotube-porphyrin supramolecular hybrid: synthesis and photophysical studies. ChemPhysChem 15(1), 100-108 (2014)

75. Zhong, Q., Diev, V.V., Roberts, S.T., Antunez, P.D., Brutchey, R.L., Bradforth, S.E., Thompson, M.E.: Fused porphyrin-singlewalled carbon nanotube hybrids: efficient formation and photophysical characterization. ACS Nano 7(4), 3466-3475 (2013)

76. Roquelet, C., Langlois, B., Vialla, F., Garrot, D., Lauret, J.S., Voisin, C.: Light harvesting with non-covalent carbon nanotubes/porphyrin compounds. Chem. Phys. 413, 45-54 (2013)

77. Bassiouk, M., Basiuk, V.A., Basiuk, E.V., Alvarez-Zauco, E., Martinez-Herrera, M., Rojas-Aguilar, A., Puente-Lee, I.: Noncovalent functionalization of single-walled carbon nanotubes with porphyrins. Appl. Surf. Sci. 275, 168-177 (2013)

78. Zakeri, M., Moghadam, M., Mohammadpoor-Baltork, I., Tangestaninejad, S., Mirkhani, V., Khosropour, A.R.: Multiwall carbon nanotube supported manganese(III) tetraphenylporphyrin: efficient catalysis for epoxidation of alkenes with $\mathrm{NaIO}_{4}$ under various reaction conditions. J. Coord. Chem. 65(7), 1144-1157 (2012)

79. Gupta, J., Vijayan, C., Maura, S.K., Goswami, D.: Ultrafast nonlinear optical response of carbon nanotubes functionalized with water soluble porphyrin. Optics Commun. 285(7), 1920-1924 (2012)

80. Zagal, J.H., Griveau, S., Santander-Nelli, M., Granados, S.G., Bedioui, F.: Carbon nanotubes and metalloporphyrins and metallophthalocyanines-based materials for electroanalysis. J Porphyr. Phthalocyanines 16(7-8), 713-740 (2012)

81. Liu, S., Mannsfeld, S.C.B., LeMieux, M.C., Lee, H.W., Bao, Z.: Organic semiconductor-carbon nanotube bundle bilayer field effect transistors with enhanced mobilities and high on/off ratios. Appl. Phys. Lett. 92, 053306(1-3) (2008)

82. Baba, A., Matsuzawa, T., Sriwichai, S., Ohdaira, Y., Shinbo, K., Kato, K., Phanichphant, S., Kaneko, F.: Enhanced photocurrent generation in nanostructured chromophore/carbon nanotube hybrid layer-by-layer multilayers. J. Phys. Chem. C 114(35), 14716-14721 (2010)

83. Sandanayaka, A.S.D., Chitta, R., Subbaiyan, N.K., D’Souza, L., Ito, O., D'Souza, F.: Photoinduced charge separation in ionpaired porphyrin-single-wall carbon nanotube donor-acceptor hybrids. J. Phys. Chem. C 113(30), 13425-13432 (2009)

84. Pagona, G., Sandanayaka, A.S.D., Araki, Y., Fan, J., Tagmatarchis, N., Yudasaka, M., Iijima, S., Ito, O.: Electronic interplay on illuminated aqueous carbon nanohorn-porphyrin ensembles. J. Phys. Chem. B 110(42), 20729-20732 (2006)

85. Guldi, D.M., Rahman, G.M.A., Jux, N., Balbinot, D., Hartnagel, U., Tagmatarchis, N., Prato, M.: Functional single-wall carbon nanotube nanohybrids-associating SWNTs with water-soluble enzyme model systems. J. Am. Chem. Soc. 127(27), 9830-9838 (2005)

86. Chua, C.K., Pumera, M.: Chemical reduction of graphene oxide: a synthetic chemistry viewpoint. Chem. Soc. Rev. 43(1), 291-312 (2014)

87. Mahmood, N., Zhang, C., Yin, H., Hou, Y.: Graphene-based nanocomposites for energy storage and conversion in lithium batteries, supercapacitors and fuel cells. J. Mater. Chem. A 2(1), 15-32 (2014)

88. Tour, J.M.: Top-down versus bottom-up fabrication of graphene-based electronics. Chem. Mater. 26(1), 163-171 (2014)

89. Ruiz-Garcia, C., Darder, M., Aranda, P., Ruiz-Hitzky, E.: Toward a green way for the chemical production of supported graphenes using porous solids. J. Mater. Chem. A 2(7), 2009-2017 (2014)

90. Allen, M.J., Tung, V.C., Kaner, R.B.: Honeycomb carbon: a review of graphene. Chem. Rev. 110(1), 132-145 (2010)

91. Geim, A.K.: Graphene: status and prospects. Science 324(5934), 1530-1534 (2009)

92. Bolotin, K.I., Sikes, K.J., Jiang, Z., Klima, M., Fudenberg, J., Hone, J., Kim, P., Stormer, H.L.: Ultrahigh electron mobility in suspended graphene. Solid State Commun. 146, 351-355 (2008)

93. Sur, U.K.: Graphene: the two-dimensional carbon nanomaterial. Nano Sci. Nano Technol. 7(4), 156-161 (2013)

94. Palermo, V.: Not a molecule, not a polymer, not a substrate... the many faces of graphene as a chemical platform. Chem. Commun. 49(28), 2848-2857 (2013)

95. Ye, T.-X., Ye, S.-I., Chen, D.-M., Chen, Q.-A., Qiu, B., Chen, X.: Spectroscopic characterization of tetracationic porphyrins and their noncovalent functionalization with graphene. Spectrochim. Acta A 86, 467-471 (2012)

96. Park, S., Ruoff, R.S.: Chemical methods for the production of graphenes. Nat. Nanotechnol. 4, 217-224 (2009)

97. Nuvoli, D., Valentini, L., Alzari, V., Scognamillo, S., Bon, S.B., Piccinini, M., Illescas, J., Mariani, A.: High concentration fewlayer graphene sheets obtained by liquid phase exfoliation of graphite in ionic liquid. J. Mater. Chem. 21, 3428-3431 (2011)

98. Lotya, M., King, P.J., Khan, U., De, S., Coleman, J.N.: Highconcentration, surfactant-stabilized graphene dispersions. ACS Nano 4, 3155-3162 (2010)

99. Economopoulos, S.P., Rotas, G., Miyata, Y., Shinohara, H., Tagmatarchis, N.: Exfoliation and chemical modification using microwave irradiation affording highly functionalized graphene. ACS Nano 4, 7499-7507 (2010)

100. Skaltsas, T., Karousis, N., Yan, H.J., Wang, C.R., Pispas, S., Tagmatarchis, N.: Graphene exfoliation in organic solvents and switching solubility in aqueous media with the aid of amphiphilic block copolymers. J. Mater. Chem. 22, 21507-21512 (2012)

101. Yang, Q., Pan, X.J., Huang, F., Li, K.C.: Fabrication of highconcentration and stable aqueous suspensions of graphene nanosheets by noncovalent functionalization with lignin and cellulose derivatives. J. Phys. Chem. C 114, 3811-3818 (2010)

102. Zhang, X.Q., Feng, Y.Y., Tang, S.D., Feng, W.: Preparation of a graphene oxide-phthalocyanine hybrid through strong $\pi-\pi$ interactions. Carbon 48, 211-216 (2010)

103. Ghosh, A., Rao, K.V., George, S.J., Rao, C.N.R.: Noncovalent functionalization, exfoliation, and solubilization of graphene in water by employing a fluorescent coronene carboxylate. Chem. Eur. J. 16, 2700-2704 (2010)

104. Chen, J.H., Cullen, W.G., Jang, C., Fuhrer, M.S., Williams, E.D.: Defect scattering in graphene. Phys. Rev. Lett. 102, 236805 (4 pages) (2009)

105. Khan, U., Porwal, H., O’Neill, A., Nawaz, K., May, P., Coleman, J.N.: Solvent-exfoliated graphene at extremely high concentration. Langmuir 27, 9077-9082 (2011) 
106. Skaltsas, T., Pispas, S., Tagmatarchis, N.: Photoinduced chargetransfer interactions on a graphene/block copolymer electrostatically bound to tetracationic porphyrin in aqueous media. Chem. Eur. J. 19(28), 9286-9290 (2013)

107. Malig, J., Stephenson, A.W.I., Wagner, P., Wallace, G.G., Officer, D.L., Guldi, D.M.: Direct exfoliation of graphite with a porphyrin - creating functionalizable nanographene hybrids. Chem. Commun. 48, 8745-8747 (2012)

108. Mensing, J.P., Kerdcharoen, T., Sriprachuabwong, C., Wisitsoraat, A., Phokharatkul, D., Lomas, T., Tuantranont, A.: Facile preparation of graphene-metal phthalocyanine hybrid material by electrolytic exfoliation. J. Mater. Chem. 22, 17094-17099 (2012)

109. Katsukis, G., Malig, J., Schulz-Drost, C., Leubner, S., Jux, N., Guldi, D.M.: Toward combining graphene and QDs: assembling CdTe QDs to exfoliated graphite and nanographene in water. ACS Nano 6, 1915-1924 (2012)

110. Zhu, H.R., Huang, P., Jing, L., Zuo, T.S., Zhao, Y.L., Gao, X.Y.: Microstructure evolution of diazonium functionalized graphene: a potential approach to change graphene electronic structure. J. Mater. Chem. 22, 2063-2068 (2012)

111. Dong, X.C., Long, Q., Wei, A., Zhang, W.J., Li, L.J., Chen, P., Huang, W.: The electrical properties of graphene modified by bromophenyl groups derived from a diazonium compound. Carbon 50, 1517-1522 (2012)

112. Grass, R.N., Athanassiou, E.K., Stark, W.J.: Covalently functionalized cobalt nanoparticles as a platform for magnetic separations in organic synthesis. Angew. Chem. Int. Ed. 46, 4909-4912 (2007)

113. Schätz, A., Grass, R.N., Stark, W.J., Reiser, O.: TEMPO supported on magnetic C/Co-nanoparticles: a highly active and recyclable organocatalyst. Chem. Eur. J. 14, 8262-8266 (2008)

114. Goncalves, G., Marques, P.A.A.P., Granadeiro, C.M., Nogueira, H.I.S., Singh, M.K., Grácio, J.: Surface modification of graphene nanosheets with gold nanoparticles: the role of oxygen moieties at graphene surface on gold nucleation and growth. Chem. Mater. 21, 4796-4802 (2009)

115. Lightcap, I.V., Murphy, S., Schumer, T., Kamat, P.V.: Electron hopping through single-to-few-layer graphene oxide films. Sideselective photocatalytic deposition of metal nanoparticles. J. Phys. Chem. Lett. 3, 1453-1458 (2012)

116. Williams, G., Seger, B., Kamat, P.V.: TiO2-graphene nanocomposites. UV-Assisted photocatalytic reduction of graphene oxide. ACS Nano 2, 1487-1491 (2008)

117. Lei, W., Si, W., Xu, Y., Gu, Z., Hao, Q.: Conducting polymer composites with graphene for use in chemical sensors and biosensors. Microchim. Acta 181(7-8), 707-722 (2014)

118. Kim, H., Lim, H.-D., Kim, J., Kang, K.: Graphene for advanced $\mathrm{Li} / \mathrm{S}$ and $\mathrm{Li} /$ air batteries. J. Mater. Chem. A 2(1), 33-47 (2014)

119. Maiti, U.N., Lee, W.J., Lee, J.M., Oh, Y., Kim, J.Y., Kim, J.E., Jongwon, H., Tae, H., Kim, S.O.: 25-th Anniversary article: chemically modified/doped carbon nanotubes \& graphene for optimized nanostructures \& nanodevices. Adv. Mater. 26(1), 40-67 (2014)

120. Li, X., Zhang, G, Wu, G., Chen, H., Culcer, D., Zhang, Z.: Proximity effects in topological insulator heterostructures. Condensed Matter. arXiv:1401.4061v1, 1-10 (2014) (arXiv.org, e-Print Archive)

121. Yoo, B.M., Shin, H.J., Yoon, H.W., Park, H.B.: Graphene and graphene oxide and their uses in barrier polymers. J. Appl. Polym. Sci. 131(1), 39628 (1-23) (2014)

122. Dresselhaus, M.S.: What's next for low-dimensional materials? Mater. Res. Lett. 2(1), 1-9 (2014)

123. Wang, Q., Lei, J., Deng, S., Zhang, L., Ju, H.: Graphene-supported ferric porphyrin as a peroxidase mimic for electrochemical DNA biosensing. Chem. Commun. 49(9), 916-918 (2013)
124. Jahan, M., Bao, Q., Loh, K.P.: Electrocatalytically active graphene-porphyrin MOF composite for oxygen reduction reaction. J. Am. Chem. Soc. 134(15), 6707-6713 (2012)

125. Khaderbad, M.A., Tjoa, V., Rao, M., Phandripande, R., Madhu, S., Wei, J., Ravikanth, M., Mathews, N., Mhaisalkar, S.G., Rao, V.R.: Fabrication of unipolar graphene field-effect transistors by modifying source and drain electrode interfaces with zinc porphyrin. ACS Appl. Mater. Interfaces 4(3), 1434-1439 (2012)

126. Guo, C.X., Lei, Y., Li, C.M.: Porphyrin functionalized graphene for sensitive electrochemical detection of ultratrace explosives. Electroanalysis 23(4), 885-893 (2011)

127. Castellanos-Gomez, A.A., van Wees, B.J.: Band gap opening of graphene by noncovalent $\pi-\pi$ interaction with porphyrins. Graphene 2(3), 102-108 (2013)

128. Hermanns, C.F., Tarafder, K., Bernien, M., Krueger, A., Chang, Y.-M., Oppeneer, P.M., Kuch, W.: Magnetic coupling of porphyrin molecules through graphene. Adv. Mater. 25(25), 3473-3477 (2013)

129. Zhu, M., Li, Z., Xiao, B., Lu, Y., Du, Y., Yang, P., Wang, X.: Surfactant assistance in improvement of photocatalytic hydrogen production with the porphyrin noncovalently functionalized grapheme nanocomposite. ACS Appl. Mater. Interfaces 5(5), 1732-1740 (2013)

130. Geng, J.X., Jung, H.T.: Porphyrin functionalized graphene sheets in aqueous suspensions: from the preparation of graphene sheets to highly conductive graphene films. J. Phys. Chem. C 114, 8227-8234 (2010)

131. Xu, Y.X., Zhao, L., Bai, H., Hong, W.J., Li, C., Shi, G.Q.: Chemically converted graphene induced molecular flattening of 5,10,15,20-tetrakis(1-methyl-4-pyridinio)porphyrin and its application for optical detection of cadmium(II) ions. J. Am. Chem. Soc. 131, 13490-13497 (2009)

132. Catheline, A., Vallés, C., Drummond, C., Ortolani, L., Morandi, V., Marcaccio, M., Iurlo, M., Paolucci, F., Pénicaud, A.: Graphene solutions. Chem. Commun. 47, 5470-5472 (2011)

133. Ahmed, A., Gordon, R.: Single molecule directivity enhanced Raman scattering using nanoantennas. Nano Lett. 12(5), 2625-2630 (2012)

134. Murphy, S., Huang, L., Kamat, P.V.: Reduced graphene oxidesilver nanoparticle composite as an active SERS material. J. Phys. Chem. C 117, 4740-4747 (2013)

135. Grabowska, I., Singleton, D.G., Stachyra, A., Gora-Sochacka, A., Sirko, A., Zagorski-Ostoja, W., Radecka, H., Stulz, E., Radecki, J.: A highly sensitive electrochemical genosensor based on Co-porphyrin-labelled-DNA. Chem. Commun. 50, 4196-4199 (2014)

136. Si, L., He, H., Zhu, K.: 8-Hydroxylquinoline-conjugated porphyrins as broadband light absorbers for dye-sensitized solar cells. New J. Chem. 38(4), 1565-1572 (2014)

137. Vaishnavi, E., Renganthan, R.: "Turn-on-off-on" fluorescence switching of quantum dots-cationic porphyrin nanohybrid: a sensor for DNA. Analyst 139(1), 225-234 (2014)

138. Thandu, M., Rapozzi, V., Xodo, L., Albericio, F., Comuzzi, C., Cavalli, S.: "Clicking" porphyrins to magnetic nanoparticles for photodynamic therapy. ChemPlusChem 79(1), 90-98 (2014)

139. Yoosaf, K., Iehl, J., Nierengarten, I., Hmadeh, M., AlbrechtGary, A.-M., Nierengarten, J.-F., Armaroli, N.: A supramolecular photosynthetic model made of a multiporphyrinic array constructed around a C60 core and a C60-imidazole derivative. Chemistry 20(1), 223-231 (2014)

140. Jovanovic, T., Koruga, D., Jovancicevic, B.: Advances in chromatographic separation on $\mathrm{Al}_{2} \mathrm{O}_{3}$ and spectroscopic characterization of the higher fullerenes. Fullerenes, Nanotub., Carbon Nanostruct. 22(4), 384-396 (2014)

141. Tzirakis, M.D., Gisselbrecht, J.-P., Boudon, C., Trapp, N., iederich, F.: Alleno-acetylenic scaffolding for the construction 
of axially chiral C60 dimers. Tetrahedron, (2014, in press) 10. 1016/j.tet.2014.02.088

142. Kraft, A., Gsaenger, M., Beuerle, F.: Arranging fullerenes through hydrogen bonding. Eur. J. Org. Chem. 2014(3), 523-528 (2014)

143. Li, C.A., Han, K.N., Pham, X.-H., Seong, G.H.: A single-walled carbon nanotube thin film-based $\mathrm{pH}$-sensing microfluidic chip. Analyst 139(8), 2011-2015 (2014)

144. Chua, C.L., Yeoh, K.H., Woon, K.L.: Hybrid carbon nanotube/ polymer heterointerface organic field effect transistor. Thin Solid Films 556, 495-498 (2014)

145. Sevilla, M., Yu, L., Zhao, L., Ania, C.O., Titiricic, M.-M.: Surface modification of CNTs with N-Doped carbon: an effective way of enhancing their performance in supercapacitors. ACS Sustain. Chem. Eng. 2(4), 1049-1055 (2014)
146. Serrano, M.C., Gutierrez, M.C., del Monte, F.: Role of polymers in the design of 3D carbon nanotube-based scaffolds for biomedical applications. Prog. Polym. Sci. 39(7), 1448-1471 (2014)

147. Hartley, C.S.: Graphene synthesis: nanoribbons from the bottom-up. Nature Chem. 6(2), 91-92 (2014)

148. Ciesielski, A., Samori, P.: Graphene via sonication assisted liquidphase exfoliation. Chem. Soc. Rev. 43(1), 381-398 (2014)

149. Norimatsu, W., Kusunoki, M.: Epitaxial graphene on SIC(0001): advances and perspectives. Phys. Chem. Chem. Phys. 16(8), 3501-3511 (2014)

150. Glazov, M.M., Ganichev, S.D.: High frequency electric field induced nonlinear effects in graphene. Phys. Rep. 535(3), 101-138 (2014) 